\title{
Dental Caries and Severity of Gingivitis Among 12-14 Year Old Children in a School of Vadodara District: A Cross-Sectional Study
}

\author{
Pardasani Sapna A1, Parekh Sahaj R ${ }^{2}$, Jasuma Rai ${ }^{3}$, Patel Akshit P4, Nanavati Vishwa $\mathbf{K}^{\mathbf{5}}$ \\ ${ }^{1}$ B.D.S, MPH Epidemiologist, Tennessee Department of Health, USA. \\ ${ }^{2}$ B.D.S, MPH, University of Memphis, USA. \\ ${ }^{3}$ Professor, Department of Periodontology, Sumandeep Vidyapeeth, India. \\ ${ }^{4}$ B.D.S, DA, EFDA, DMD candidate, Konberg School of Dental Medicine, USA. \\ ${ }^{5}$ B.D.S, MHA (USA), Baroda Health Institute and Research Centre Vadodara, India.
}

Research Article

Address for Correspondence Author

Dr. Pardasani Sapna A; B.D.S, MPH Epidemiologist, Tennessee Department of Health, USA.

E-mail: sapnapardasani38@gmail.com

Crossref doi: https://doi.org/10.36437/ijdrd.2020.2.3.E

\begin{abstract}
Background: The dental caries and gingivitis are considered as one of the most prevalent diseases in the general population. If dental caries and gingivitis are assessed at an early age, it might prevent the risk of endodontic and periodontal diseases in the future. This intervention is effective, especially among teenagers. The aim of the study was to perceive the prevalence of dental caries and gingivitis in children aged 12 to 14 years residing in a rural area of Vadodara city.

Methods: It is a cross-sectional observational study with a total sample size of 339 in a secondary school of Vadodara district. DMFT index and CPITN index were recorded with No. 23 explorer and CPITN-E probes respectively, and a mouth mirror (Instruments were autoclaved prior to use). One-way Anova test and student t-test were used for analysis.

Results: The prevalence of dental caries amongst participants was found to be $97.7 \%$ and that of gingivitis was found to be $75 \%$ (approximately).

Conclusion: Children belonging to the Vadodara district have a high risk of getting an endodontic and periodontal infection in the future, indicating the need for oral health education and promotion.
\end{abstract}

Keywords: Dental Caries, Gingivitis, DMFT, CPITN

\section{Introduction}

Oral health is now recognized as equally important in relation to general health, so oral hygiene is the most important factor in terms of the prevention of oral diseases. The oral health concern of an individual depends upon person to person. From childhood to adolescence is an influential stage in people's lives when lifelong sustainable oral health-related behaviors, as well as beliefs and attitudes, are being developed.

Studies have shown that children are particularly receptive during this period and earlier the habits are established, the longer lasting the impact. Children may also be equipped with personal skills that enable them 
to make healthy decisions, to adopt a healthy lifestyle, and to deal with stressful situations such as violence and conflicts. Teenage is a group who is frequently exposed to above-stated factors; hence school may be considered an ideal setting for conducting evaluation and intervention health programs. ${ }^{1}$

Dental caries and gum disease are multifactorial-chronic diseases, which if not prevented at initial stages may lead to a need for endodontic and/or periodontic treatment. Teeth play a vital role in one's appearance, hence student that lose their teeth due to caries are at high risk of suffering from abstensim. Moreover, these children are twelve times more likely to have restricted activity days including missing school as compared to others. ${ }^{1,2}$ Periodontal diseases are the ones of the most prevalent oral diseases that get their roots early in childhood. Hence if gingivitis and periodontitis are assessed in an early stage it will minimize the chance of tooth loss. ${ }^{4}$ World Health Organization has recommended the age group between 12 to 15 as the index ages for oral health assessment. ${ }^{3}$ Henceforth, this study will help to assess the severity of dental caries and gingivitis. In our literature search, we found that no study is done to date to find the prevalence of dental caries and gingivitis among 12 to 14-year-old children. Hence, the results obtained from this study will act as a baseline study to conduct evaluation and intervention studies on large scale adolescence populations of rural areas in Vadodara city.

\section{Materials and Methods}

The study was conducted in a Secondary school of Vadodara district in the year of 2016. Prior written permission from the school head was taken. Before the conduction of the study, the parent information sheet was distributed, following which informed consent and assent form was obtained from participants.

\section{Power Analysis and data collection}

In order to estimate a $40 \%$ prevalence of dental caries with $20 \%$ relative precision and $1 \%$ risk, a minimum of 250 samples was estimated.

Data collection was performed in a WHO questionnaire, the data was later entered in the MS excel 2010 by one of the coinvestigators following which data control was performed by the primary investigator under the guidance of statistician.

\section{Study Population Size}

The subjects were selected based on inclusion and exclusion criteria. Inclusion criteria: Subjects in the age range of 12 to 14 years old, subjects who are systemically healthy and present with their school diary (for noting their socio-economic status based on parents' monthly income)-Kuppuswamy classification of socioeconomic status-2016 ${ }^{5}$, subjects whose parents have submitted the written consent form. Potential participants were added to exclusion criteria if they reported with physical and/or mental disability and undergoing orthodontic treatment. Also, participants with developmental anomalies were excluded.

Out of total student (600) present in school, we had 351 students that belong to our age group of interest (12 to 14 years), of which five of the participants did not submitted the parent consent form, four were not present at the day of study and three were having malocclusion. Hence, a total of 339 pupils were included into the study. Prior to the conduction of examination, the nature and the purpose of the study was explained to the students and parents.

\section{Examination}

The scheduled days (Friday and Saturday) were selected based on the convenience of the school. Prior to the examination, a form containing questions relating to the demographic details of students were used, following 
which patients were asked to rinse the mouth with normal water. The clinical examination was conducted by two investigators and the other two assistants were recording the details of the examination. The examination was conducted in a room of the school, using a headlamp, one-sided No. 5 mouth mirror, CPITN-E probe, Explorer No. 23, sterilized gauze compress to dry the teeth, tweezer and a kidney tray. The students were examined by sitting in a normal chair and dentist standing in front of them. The Decayed Missing Filled Teeth index (DMFT) was recorded first followed by the Community Periodontal Index (CPI).

\section{Caries Diagnosing Criteria}

Criteria by " Henry T. Klein, Carolle E. Palmer, and Knutson J.W. in1938, modified in 1987"6 was applied to record caries. All the teeth were examined from the upper right quadrant to the upper left quadrant following the lower left quadrant to the lower right quadrant. The teeth not counted were un-erupted teeth, congenitally missing teeth or supernumerary teeth, teeth removed for reasons other than dental caries, and primary teeth retained in the permanent dentition. When a carious lesion(s) or both carious lesion(s) and restoration were present, the tooth was recorded as a D. When a tooth was an extracted one due to caries, it was recorded as an M. When a permanent or temporary filling was present, or when a filling was defective but not decayed, it was counted as an F. Teeth restored for reasons other than caries were not counted as an F. Accordingly scores were given to each tooth, hence caries status and the experience was determined.

\section{Gingival Diagnosing Criteria}

For assessing the gingival condition, we used "Community Periodontal Index of Treatment Needs (CPITN)" developed by J Ainamo, D Barmes, G Beargie, T Cutress, J Martin and J S-Infirriin 1982. CPITN-E probe and mouth mirror was used. The mouth was divided into six parts (sextants). The score was identified by examination of specified index teeth.

16 (Upper right first molar), 11 (Upper right first Incisor) 26 (Upper left first molar) 36 (Lower right first molar) 31 (Lower right first incisor) 46 (Lower left first molar). SCORE CRITERIA: 0: No periodontal disease, 1: Bleeding on probing, 2: Calculus with plaque seen or felt by probing, 3: Pathological pocket 4-5 $\mathrm{mm}, 4$ : Pathological pocket $6 \mathrm{~mm}$ or more, $\mathrm{x}$ : When only 1 tooth or no tooth is present. ${ }^{7}$

\section{Beneficiary}

This study intends to estimate the prevalence of dental caries and gingivitis in 12 to 14 years old age group and the need for intervention in them. Apart from collecting data, we wrote a note of oral hygiene status in the student's diary as well, so their parents can know about the oral hygiene status of their child. Following the collection of data, we had kept a small seminar of proper brushing technique and its importance was conducted in which we included students and all staff members. In the end, we distributed a toothpaste and a toothbrush.

\section{Statistical Analysis}

The SPSS-17 software was used to determine the statistical results of this study. The significance level used for comparison was 0.05 . The data distribution was normal, hence the means between different age groups were compared with the ANOVA test. Student T-test was used to compare if there is any significant difference in prevalence amongst different gender.

\section{Results}

Examinations were performed on 339 pupils aged 12 to 14 years. A larger percentage of students were males. All participants belonged from the rural area. The mean DMFT index found for the age group 12 to 14 years was 
2.510.082), moreover it was noticed that $97.7 \%$ of the total sample had a DMFT status of above 1.Table: 2 shows the means of DMFT is highest amongst the 14 years older age group. The Anova test found a significant difference between the mean DMFT index and age groups ( $\mathrm{P}=0.0383, \mathrm{~F} 0=3.308$ ) (Table: 3 ). Moreover, the independent T-test (Table: 4) revealed that the prevalence of DMFT in males and females is significantly different $(\mathrm{t}=-1.979$, $\mathrm{p}$-value $=0.009)$. It reveals that males are more prone to dental caries than females.

\begin{tabular}{|l|l|}
\hline \multicolumn{2}{|c|}{$\begin{array}{c}\text { Frequency Distribution of Demographic } \\
\text { Variables Among Study Subjects }\end{array}$} \\
\hline Gender & Frequency (\%) \\
\hline Male & 57.6 \\
\hline Female & 42.4 \\
\hline DMFT score & \\
\hline 0 & 2.3 \\
\hline 1 & 19.7 \\
\hline 2 & 34.8 \\
\hline 3 & 22.0 \\
\hline 4 & 4.5 \\
\hline 5 & 14.4 \\
\hline 6 & 1.5 \\
\hline 8 & 0.8 \\
\hline CPI & \\
\hline 0 & 25.04 \\
\hline 1 & 34.4 \\
\hline 2 & 36.33 \\
\hline 3 & 2.23 \\
\hline
\end{tabular}

Table1

*DMFT: Decayed Missing and Filled Index, CPI: Community Periodontal Index, \%: Percentage, Scoring Criteria for Decay Missing Filled Teeth: Scored according to number of teeth Decayed and/or missing and/or filled. Score criteria for Community Periodontal Index: 0: No periodontal disease, 1: Bleeding on probing, 2: Calculus with plaque seen or felt by probing, 3: Pathological pocket $4-5 \mathrm{~mm}, 4$ : Pathological pocket $6 \mathrm{~mm}$ or more, $x$ :When only 1 tooth or no tooth are present.7

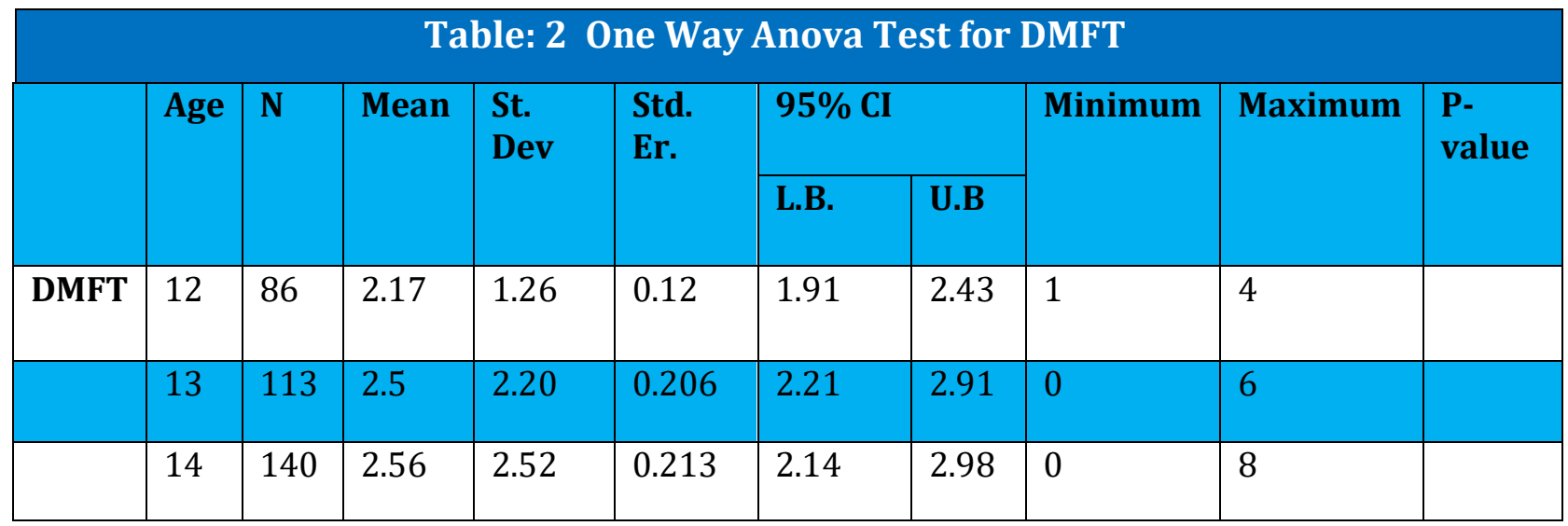

*DMFT: Decayed Missing Filled Teeth N: Total sample is respective age group, St. Dev: Standard Deviation, Std.

Er.: Standard Error, CI: Confidence Interval,

LB: lower bound, UB: Upper bound, significant $p$ value $=0.05$ 


\begin{tabular}{|l|l|l|l|l|l|l|}
\hline \multicolumn{7}{|c|}{ Table 3: ANOVA Table } \\
\hline & & SS & DF & MS & F & $\begin{array}{l}\text { P-value } \\
(\boldsymbol{\alpha = 0 . 0 5 )}\end{array}$ \\
\hline DMFT & BG & 11.66 & 2 & 5.83 & 3.03 & 0.0383 \\
\hline & WG & 460.543 & 261 & 1.765 & & \\
\hline & Total & 461.985 & 263 & & & \\
\hline
\end{tabular}

*SS: Sum of Squares, df: Degree of freedom, MS: Mean Square, BG: Between Groups, WG: Within Groups, $\alpha=$ statistical significance level

\begin{tabular}{|l|l|l|l|l|l|l|l|}
\hline \multicolumn{2}{|c|}{ Table 4: Independent T-test } \\
\hline & Sex & $\mathbf{N}$ & Mean & Std. Dev. & t-Value & P-value & $\boldsymbol{\alpha}$ \\
\hline DMFT & Male & 152 & 2.42 & 1.071 & -1.979 & 0.009 & 0.05 \\
\hline & Female & 137 & 2.09 & 1.606 & & & \\
\hline
\end{tabular}

*DMFT: Decayed Missing Filled Teeth N: Total number of sample in respect of gender, Std. Dev.: Standard Deviation, $\alpha$ : statistical significance level

\begin{tabular}{|l|l|l|l|l|l|l|l|l|l|}
\hline \multicolumn{10}{|c|}{ Table: 5 One Way Anova Test for CPI } \\
\hline & Age & N & Mean & St. Dev & Std. Er. & 95\% CI & Minimum & Maximum \\
\cline { 5 - 9 } & & & & & & LB & UB & & \\
\hline CPI & 12 & 86 & 1.17 & 01.55 & 0.16 & 0.84 & 1.5 & 0 & 2 \\
\hline & 13 & 113 & 2.06 & 2.57 & 0.241 & 1.58 & 2.54 & 0 & 2 \\
\hline & 14 & 140 & 2.11 & 2.42 & 0.204 & 1.70 & 2.52 & 0 & 2 \\
\hline
\end{tabular}

CPI: Community Periodontal Index, N: Total sample is respective age group, St. Dev: Standard Deviation, Std. Er.: Standard Error, CI: Confidence Interval

\begin{tabular}{|l|l|l|l|l|l|l|}
\hline \multicolumn{7}{|c|}{ Table: 6 ANOVA Table for CPI index } \\
\hline & & SS & DF & MS & F & p-value \\
\hline CPI & BG & 9.66 & 2 & 4.83 & 3.06 & $<0.05$ \\
\hline & WG & 412.38 & 261 & 1.58 & & \\
\hline & Total & 422.04 & 263 & & & \\
\hline
\end{tabular}

*SS: Sum of Squares, df: Degree of freedom, MS: Mean Square, BG: Between Groups, WG: Within Groups 


\begin{tabular}{|l|l|l|l|l|l|l|}
\hline \multicolumn{7}{|c|}{ Table 7: Independent T-test } \\
\hline & Sex & N & Mean & Std. Dev & t-Value & P-value \\
\hline CPI & Male & 152 & 0.22 & 0.504 & -2.201 & 0.029 \\
\hline & Female & 137 & 0.9 & 0.569 & & \\
\hline
\end{tabular}

*CPI: Community Periodontal Index N: Total number of sample in respect of gender, Std. Dev.: Standard Deviation

In regard to the periodontal index, the prevalence of gingivitis was found to be $75 \%$ in the study population (Table 1 and Table 5). Moreover, we could conclude that there is a significant difference in treatment needs amongst different age groups and gender (Table 6 and Table 7).

\section{Discussion}

Dental Caries has been very well known for its most common prevalence (60\% to $90 \%$ ) amongst Asians. ${ }^{4}$ Moreover, India is considered as a rural country with the highest level of poverty and, dental caries and periodontal disease prevalence in its people.5,7

In one of the cross-sectional studies conducted, they concluded students had a higher prevalence of dental diseases. The main reasons were geographical environment, dietary habits, students' attitude to oral health, and lack of oral health promotion and education. Oral health education should be strengthened to get effective prevention of dental diseases. ${ }^{2}$

Henceforth, our cross-sectional survey focuses on the two most common but preventable oral diseases, dental caries, and periodontal disease which affects many teenage students. Traditionally dentists have been trained to recognize and treat diseases such as caries and periodontal disease. ${ }^{3}$ Consequently; various indices such as CPI-TN along with DMFT have been used to describe the prevalence of these diseases in the population. ${ }^{2}$

The incidence of dental caries differs upon individual biological variance and socio-economic status. Hence, to plan the best surveillance for treatment plans, there should be an identified magnitude of the disease population which can aid us in controlling or preventing the disease at a certain acceptable level. This study was specifically aimed to relate the need for oral health education camps in rural regions (with lower socioeconomic status). ${ }^{8}$

To our knowledge, no study has been conducted to assess the severity of gingivitis in children age 12 to 14 years. Hence, this study has focused on the prevalence of dental caries as well as gingivitis amongst children ages 12 to 14 years.

The present study reports the overall prevalence of dental caries index in our group was $97.7 \%$ which is higher than the reported prevalence in India according to the "National Oral Health Survey" 9, which indicates a need for oral health care and promotion in the target study population. Moreover, it was found that males were affected in high frequency than females. This result was in support of the studies conducted by Prabakar J et al (2016), Yevenes et al (2012), Arora Sachit et al (2012), Moses J (2011), and Joshi N

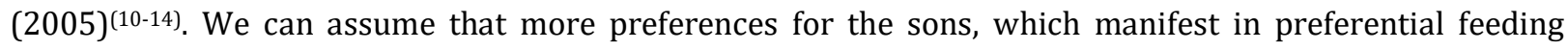
compared to might be a reason for girls being less prevalent to dental caries as compared to boys. Besides, 
the proportion of boys is higher, and given that the present study has a small sample size, these results might have occurred due to bias. Hence, this demands of study with a large sample size.

As factors such as diet intake, socioeconomic status, literacy do play a role in causing dental caries. 15,16 Hence, in order to avoid the confounding factors, we selected students from the same socioeconomic status (studying in rural school). Moreover, after conducting a student's T-test, we could conclude that there is a significant difference between the prevalence of dental caries amongst males and females.

On the same day, following the DMFT index, we did the CPITN index. This index was used to estimate the prevalence of gingivitis in children. ${ }^{17}$ after dental caries, it is the periodontal health we are concerned about. One of the studies conducted by P Aapaliya (2015) in Gujarat (2015) had revealed that the prevalence of gingivitis in the Gujarat population aged 21 to 70 years old is $75.1 \%{ }^{18}$, which is similar to the one obtained in our study. However, the age group and sample size are taken by P Aapaliya was very much different than the present study. Due to the huge sample size and inclusion of elderly people, its results seem to be more authentic. However, in this study, we included rural folks, with low socioeconomic status which lead to a high prevalence of gingivitis. Hence, we can assume that there is no major difference in the prevalence of gingivitis amongst two studies, as there is one of the other confounder causing gingivitis.

Kaur A conducted a study amongst 12 years old children in Haryana, India. He concluded that the prevalence of gingivitis in the study group from the rural group is $94 \%{ }^{19}$. The results are in accordance with our results, showing a high prevalence of gingivitis. However, Kaur A used Loe and Silness index to assess the gingivitis.

F Varas concluded that the prevalence of gingivitis amongst 6 to 8 years old is $68.5 \%$. They further specified that the gender differences were not statistically significant. The prevalence of gingivitis was $29.57 \%$, prevalence of bleeding on probing was $27.49 \%$ and $2.08 \%$ of children with gingival calculus. ${ }^{19}$ On the contrary, in the present study, we found that the study population did have score 3 i.e. pathological pocket (2.23\%). The prevalence of bleeding on probing was found to be $34.40 \%$ and the calculus was found to be $36.33 \%$. Our findings suggest that there is a need for an oral health education campaign in the concerned geographical location.

\section{Limitations}

The present study had some of the limitations such as the sample size was very small, which can overestimate the prevalence of gingivitis and dental caries. Moreover, due to the lack of equal distribution of age group, the results cannot present the authenticity as to which age group is more prevalent. We would encourage to conduct of the same study involving a large amount of population, including different schools from different zones of Vadodara district and an equal number of participants in each group.

\section{References}

1. Fotedar S, Sogi GM, Sharma Kapil, Purthi N. Oral helath status and treatment needs among 12 and 15 years old government nad private school children in Shimla city, Himachal Pradesh, India. J Int soc of Prev and Comm Dentistry. 2013; 3:44-50. [PMC free article] [PubMed]

2. Oral Health Promotion: An essential element of a health promoting schools. Geneva: 2003. [cited 6 Jan 2015 ]. [Internet] Available from: www.who.int/oral_health/media/en/orh_school_doc11.pdf. 
3. Dixit L P, Shakya A, Shrestha M, Shrestha A. (2013). Dental caries prevalence, oral health knowledge and practice among indigenous Chepang school children of Nepal. BMC Oral Health, 13(1). doi:10.1186/1472-6831-13-20

4. Bali RK, Mathur VB, Talwar PP, Chanana HB. National Oral Health Survey \& Fluoride Mapping, 20022003, India. Delhi: Dental Council of India; 2004.

5. Bairwa M, Rajput, M, Sachdeva S. (2013). Modified kuppuswamy's socioeconomic scale: Social researcher should include updated income criteria, 2012. India.

6. Organization, W. H. (1971). Oral Health Surveys: Basic Methods. Biometrics, 27(4), 1111. doi: https://doi.org/10.2307/2528861.

7. Kothia N. R., Bommireddy V. S., Devaki, T., Vinnakota, N. R.,et al(2015). Assessment of the Status of National Oral Health Policy in India. International Journal of Health Policy and Management, 4(9), 575-581. doi: https://doi.org/10.15171/ijhpm.2015.137

8. Narvai PC, Frazão P, Roncalli AG, Antunes JLF. Dental caries in Brazil: decline, polarization, inequality and social exclusion. Rev PanamSalud Publica. 2006; 19(6):385-93. https://doi.org/10.1590/s1020$\underline{49892006000600004}$

9. National Oral Health Care Programme - AIIMS.

10. Prabakar J, John J, Srisakthi D. Prevalence of dental caries and treatment needs among school going children of Chandigarh. Indian J Dent Res 2016; 27:547-52. http://www.ijdr.in/text.asp?2016/27/5/547/195683

11. Arora Sachit A, Sumeet S, Puneet A, Darrel S, Anil C. Prevalence of dental caries among pre-school children of greater Noida city, UP (India). Indian J Dent Sci 2012; 4:4-6.

12. Yevenes I, Bustos BC, Ramos AA, Espinoza RM, Jara MN, Petrasic Smith L. Prevalence of dental caries in pre-school children in Penaflor, Santiago, Chile. Rev OdontoCienc2009; 24:116-9.

13. Moses J, Rangeeth BN, Gurunathan D. Prevalence of dental caries, socio-economic status and treatment needs among 5 to 15 year old school going children of Chidambaram. J Clin Diagn Res 2011;5:146-51.https://www.jcdr.net/article fulltext.asp?issn=0973709x\&year=2011\&volume=5\&issue=1\&page $=146 \&$ issn=0973-709x\&id=1156

14. Joshi N, Rajesh R, Sunitha M. Prevalence of dental caries among school children in Kulasekharam village: A correlated prevalence survey. J Indian Soc PedodPrev Dent 2005; 23:138-40. http://www.jisppd.com/text.asp?2005/23/3/138/16887

15. Asanova-Rosado AJ, Medina-Solís CE, Casanova-Rosado JF, Vallejos-Sánchez AA, Maupomé G, AvilaBurgos L. Dental caries and associated factors in Mexican schoolchildren aged 6-13 years. Acta OdontolScand 2005; 63:245-51. https://doi.org/10.1080/00016350510019865

16. Basha S, Swamy HS. Dental caries experience, tooth surface distribution and associated factors in 6and 13- year- old school children from Davangere, India. J Clin Exp Dent 2012; 4:E210-6. http://dx.doi.org/10.4317/jced.50779

17. Varas $\mathrm{F}$ et al. Periodontal status and treatment needs of children from 6 to 8 years old in the Santiago Metropolitan Region of Chile. Rev OdontoCienc 2011; 26(1):10-15. https://doi.org/10.1590/S1980$\underline{65232011000100005}$

18. Aapaliya $P$ et al. Assessment of oral health among seafarers in Mundra Port, Kutch, Gujarat: a crosssectional study. Int Marit Health. 2015; 66(1):11-17. https://journals.viamedica.pl/international maritime health/article/view/IMH.2015.0004/28964

19. Kaur A. An epidemiological study to determine the prevalence and risk assessment of gingivitis in 5-, 12- and 15-year-old children of rural and urban area of Panchkula (Haryana). Indian J Dent Res. 2014 May-Jun; 25(3):294-9. http://www.ijdr.in/text.asp?2014/25/3/294/138310 
How to cite this Article: Pardasani Sapna A ${ }^{1}$, Parekh Sahaj R ${ }^{2}$, Jasuma Rai ${ }^{3}$, Patel Akshit P $^{4}$, Nanavati Vishwa K' ${ }^{5}$ : Dental Caries and Severity of Gingivitis Among 12-14 Year Old Children in a School of Vadodara District: A Cross-Sectional Study

Int. J. Drug Res. Dental Sci., 2020; 2(3): 20-28.

Crossref doi: https://doi.org/10.36437/ijdrd.2020.2.3.E

Source of Support: Nil, Conflict of Interest: Nil.

Received: 15-7-2020 Revised: 8-8-2020 Accepted: 15-8-2020 